\title{
Optimal number of biopsy specimens in the diagnosis of carcinoma of the oesophagus
}

\author{
N Lal, D K Bhasin, A K Malik, N M Gupta, K Singh, S K Mehta
}

\begin{abstract}
The study evaluated 48 patients with carcinoma of the oesophagus to assess the optimal number of biopsy specimens required to obtain the highest yield. Eight specimens were obtained from each patient and two specimens were placed serially in each of four vials. The first vial provided a positive diagnosis in $95.8 \%$ of cases. The addition of two more specimens (second vial) increased the yield to $97.9 \%$ and the fifth and sixth specimens increased the positive yield to $100 \%$. There was no statistically significant difference in the yield according to the site and the type of growth.
\end{abstract}

The advent of fibreoptic endoscopy has revolutionised early diagnosis in patients with oesophageal carcinoma. Endoscpic biopsy specimens are reported to give a positive yield in $81 \cdot 3 \% \cdot 96 \cdot 3 \%^{12}$ of cases and the addition of cytological techniques increases the diagnostic yield to $97 \%-100 \% .{ }^{13}$ In developing countries, the surgeon depends greatly on histopathological diagnosis and in the event of a negative biopsy report, the procedure has to be repeated.

While a great deal of emphasis has been laid in published reports on developing newer cytological techniques such as brush, crush, salvage, and suction cytology ${ }^{1+}$ to increase the diagnostic yield, the question of the optimal number of biopsy specimens that will give the highest yield in oesophageal cancer has not received much attention. There are studies that evaluate the optimal number of specimens required for gastric cancer, but there are few similar studies for carcinoma of the oesophagus. Carcinoma of the oesophagus is one of the commonest malignancies of the gastrointestinal tract in India, and because of this we aimed to determine the optimal number of biopsy specimens required to achieve a maximum yield in patients with this

This study was conducted on 50 patients with dysphagia who were suspected of having oesohistory, clinical examination, and barium out to have achalasia cardia, were subsequently

Informed consent was obtained from all patients. Intravenous diazepam was given as premedication and upper gastrointestinal endoscopy was performed using a forward viewing endoscope. Details of the site, extent, and type of the lesion were recorded. Eight biopsy specimens were taken from the adjacent area, carefully avoiding any haemorragic and necrotic areas. Each pair of specimens was immersed in $10 \%$ formal saline in separate vials and in the serial order in which they had been obtained. Each vial was given a code number to identify the serial order in which these specimens had been taken. The pathologist who recorded the results was not aware of the code numbers. At the end of the study, the code was broken and the results were analysed to determine the positivity rate of the first two specimens and the additional cases picked up by the subsequent biopsy specimens.

Statistical analysis was performed using the $\chi^{2}$ test with Yates's correction.

\section{Results}

Of these 48 patients with carcinoma of the oesophagus, the youngest was a woman aged 25 years and the oldest was an 80 year old man. The mean age of the patients was 52 years and the male to female ratio was $1 \cdot 3: 1.75 \cdot 0 \%$ of the growths were in the middle third of the oesophagus, $18.8 \%$ in the lower third, and $6.2 \%$ in the upper third. Most growths were polypoidal in type $(83.3 \%)$; stenosing and ulcerative

TABLE II The discordant results of endoscopic biopsy specimens in the different vials

\begin{tabular}{|c|c|c|c|c|}
\hline \multirow[b]{2}{*}{ Case no } & \multicolumn{4}{|c|}{ Results in different vials } \\
\hline & $I$ & $I I$ & $I I I$ & $I V$ \\
\hline 2 & + & + & - & + \\
\hline 9 & - & + & + & + \\
\hline 18 & + & + & + & - \\
\hline 20 & + & - & - & + \\
\hline 22 & - & - & + & - \\
\hline 24 & + & - & - & + \\
\hline 26 & + & - & - & + \\
\hline 27 & + & + & - & - \\
\hline
\end{tabular}

TABLE III The yield of endoscopic biopsy specimens from 48 patients after combining the results from successive vials

\begin{tabular}{llc}
\hline Vial no & $\begin{array}{l}\text { No of positive } \\
\text { patients }\end{array}$ & \% Positivity \\
\hline I & 46 & $95 \cdot 8$ \\
I+II & 47 & $97 \cdot 9$ \\
I+II+ III & 48 & 100 \\
I+ II + III + IV & 48 & 100 \\
\hline
\end{tabular}

TABLE I The yield of disorder.

\section{Methods} phageal carcinoma because of their medical studies. Two patients, who on endoscopy turned excluded from the study.

\author{
A K Malik \\ N M Gupta \\ S K Mehta \\ Correspondence to: \\ Dr D K Bhasin, 2129, 21-C \\ Chandigarh 160022, India. \\ Accepted for publication \\ 7 October 1991 \\ Departments of Internal \\ Gastroenterology, and \\ Education and Research, \\ Chandigarh, India \\ N Lal
}


growths constituted $10 \cdot 5 \%$ and $6 \cdot 2 \%$ of the cases respectively. As can be seen from Tables I and II, two cases were missed by the specimens in vial I. Of these two, one was picked up by the specimens in vial II and the other by the biopsy specimens in vial III. Four cases were missed by the third and fourth specimens in vial II. Three of these were picked up by first two biopsy specimens in vial $I$, and the fourth by the fifth and sixth specimens in vial III. Five cases were missed by the fifth and sixth specimens in vial III. All these cases were picked by the first two biopsy specimens in vial I. In two of these five cases, the specimens in the second vial were also positive. There were thus three cases which were negative in the second and third vials combined together. In three cases the diagnosis of carcinoma was missed by the specimens in vial IV (the seventh and eighth specimens). Two of these cases were picked up by vial I and the third by vial III. Thus, not a single case was missed by the biopsy specimens in the first three vials.

As can be seen from Table III, the first vial (that is, the first two biopsy specimens) yielded a correct diagnosis in $95 \cdot 8 \%$ of cases. Combining these results with those of the additional two biopsy specimens (vials I plus II) the positive yield of the biopsy specimens increased to $97.9 \%$ and it reached $100 \%$ when the results of six biopsy specimens (vials I, II, and III) were combined.

There was no statistically significant difference in the positive yield of biopsy specimens according to the site of the carcinoma or its type.

Based on the clinical and radiological investigations, 16 of the 48 patients were considered suitable for operation. At surgery, two patients were found inoperable because of extensive disease. The remaining 14 patients underwent transhiatal oesophagectomy.

Histopathology showed that 46 patients $(95.8 \%)$ had squamous cell carcinoma, one had small cell carcinoma and one an adenocarcinoma. When the patient with adenocarcinoma came to surgery it was found that the growth had affected only the lower end of the oesophagus. The cardia and fundus of stomach were disease free.

\section{Discussion}

Carcinoma of the oesophagus is one of the commonest gastrointestinal malignancies in India. ${ }^{5}$ The greater the delay before diagnosis, the poorer the prognosis. Because of the need for speedy diagnosis and for a higher positive yield from specimens, a great deal of stress has been laid on evolving better diagnostic cytological techniques such as brush, aspiration, suction, salvage, and imprint cytology that will improve the diagnostic yield of biopsy specimens in gastro-oesophageal malignancies. ${ }^{1-10}$

However, few data are available on the optimal number of specimens required for the diagnosis of carcinoma of the oesophagus. Most studies on the role of multiple biopsy specimens in increasing the diagnostic yield has been done in gastric cancer. ${ }^{11-13}$

Dekker and Tytgat" propose that at least 10 biopsy specimens should be taken from sus- pected malignant gastric lesions, as in eight of their total of 151 cases, only one of the ninth, 10th, and 11th biopsy specimens showed malignancy. These authors, however, did not record the order in which the biopsy specimens had been taken. Sancho Poch et $a l^{12}$ found that only one of 66 cases of gastric cancer in which eight specimens had been obtained was negative. However, these authors also did not take into account the order in which biopsy specimens had been taken. Misumi et $a l^{13}$ found that the diagnostic accuracy was $100 \%$ in gastric cancers when six or more biopsy specimens were obtained. Most of the other studies are also in gastric cancers and the number of biopsy specimens varied from $4-10 .^{61+16}$

There are many studies of the diagnostic accuracy of endoscopically performed cytological techniques in the diagnosis of carcinoma of the oesophagus. In these cytological studies, the various authors have either not mentioned the number of biopsy specimens ${ }^{17}$ or have taken varying numbers, leaving this to the judgement of the endoscopist ${ }^{3}$ rather than evaluating the optimal number of specimens needed to obtain the maximum yield. Graham et al conducted a study in which biopsy and cytology specimens were obtained from 202 consecutive patients, 27 of whom had carcinoma of the oesophagus. In each instance the authors obtained seven biopsy specimens in three groups. Group A contained the first biopsy specimen; group B biopsy specimens 2, 3, and 4; and group $C$ biopsy specimens 5,6 , and 7. In Graham's study, the first biopsy yielded a correct diagnosis in $92.6 \%$ of patients with oesophageal cancer; with four specimens accuracy went up to $96 \%$, and with seven biopsy specimens it reached $96 \cdot 3 \%$. Seven biopsy and cytology specimens yielded a diagnosis in all the cases. Based on their study, the authors recommended that at least seven endoscopic biopsy specimens should be taken in cases of gastrooesophageal malignancy.

Our study differs from that of Graham et al in that: (i) we evaluated more patients (48 $v 27)$ and the diagnostic yield of six biopsy specimens was $100 \%$; (ii) two specimens were placed in each of the four vials rather than one, three, and three pieces in three vials; and (iii) Graham et al also performed salvage cytology while in our study cytological examination was not performed as this was not the aim of the study.

In conclusion, this study shows that six biopsy specimens are likely to yield a $100 \%$ diagnosis in cases of carcinoma of the oesophagus.

1 Graham DY, Schwartz JT, Cain GD, Gyorkey F. Prospective evaluation of biopsy number in the diagnosis of esophageal and gastric carcinoma. Gastroenterology 1982; 82: 228-31.

2 Prolla JC, Reillay RW, Kironer JB, Cockerhans L. Direc vision endoscopic cytology and biopsy in the diagnosis of oesophageal and gastric tumours. Current experience. Acto Cytol 1977; 21: 399-403.

3 Young JA, Hughes HE, Lee FD. Evaluation of endoscopic brush and biopsy touch smear cytology and biopsy histology in the diagnosis of carcinoma of the lower esophagus and cardia. F Clin Pathol 1980; 33: 811-4

4 Kasugai T, Kobayashi S, Nobuyoshi K. Endoscopic cytology of oesophagus stomach and pancreas. Acta Cytol 1978; 22 . of oesoph

5 Bhansali SK. Geographical distribution of gastro intestinal cancer in India. Ind $\mathcal{F}$ Surg 1968; 30: 33-7.

6 Winawer SJ, Posner G, Lightdale CJ, Sherlock P, Melamed $M$, Fostner JG. Endoscopic diagnosis of avdanced gastric cancer. Factors influencing yield. Gastroenterology 1975; 69: $1183-7$ 
7 Chambers LA, Clark WE. The endscopic diagnosis of gastroesophageal malignancy: A cytological review. Acta Cyto 1986; 30: $110-4$.

8 Bhasin DK, Kochhar R, Rajwanshi A, Gupta SK, Mehta SK. Endoscopic Suction Cytology in Upper Gastrointestinal Tract Malignancy. Acta Cytol 1988; 32: 452-4.

9 Bhasin DK, Rajwanshi A, Kochhar R, Mehta SK. Brush cytology for colorectual cancer. Lancet 1989; i: 1133-4.

10 Kochhar R, Bhasin DK, Rajwanshi A, Gupta SK, Malik AK Mehta SK. Crush smears preparations of gastroesophageal malignancies. Acto

11 Dekker W, Tytgat GN. Diagnostic accuracy of fiberendoscopy in the detection of upper intestinal malignancy. A follow up analysis. Gastroenterology 1977; 73: 710-4.

12 Sancho-Poch FJ, Balanzo J, Ocana J. An evaluation of gastric biopsy in the diagnosis of gastric cancer. Gastrointest Endos $1978 ; 24: 281-2$
13 Misumi A, Mori K, Ikeda T, et al. Evaluation of fibergastroscopic biopsy in the diagnosis of gastric cancer. A study of 339 cases. Gastroenterol fpn 1978; 13: 255-63.

14 Hatfield ARW, Slavin G, Segal AW. Importance of the site of endoscopic gastric biopsy in ulcerating lesions of the stomach. Gut 1975; 16: 884-6.

15 Johansen A, Sikjaer B. Gastroscopic biopsy. Reliability of histological diagnosis with special reference to the single histological diagnosis with special reference
biopsy. Scand $\mathcal{F}$ Gastroenterol $1975 ; 10: 453-8$.

16 Witzel L, Halter F, Grelillat PA, Scheurer U, Keller M Evaluation of specific value of endoscopic biopsies and brush cytology for malignancies of the oesophagus and stomach. Gut 1976; 17: 375-7.

17 Keighley MRB, Thompson H, Moore J, et al. Comparison of brush cytology before or after biopsy of diagnosis of gastric carcinoma. BrF Surg 1979; 66: 246-7. 